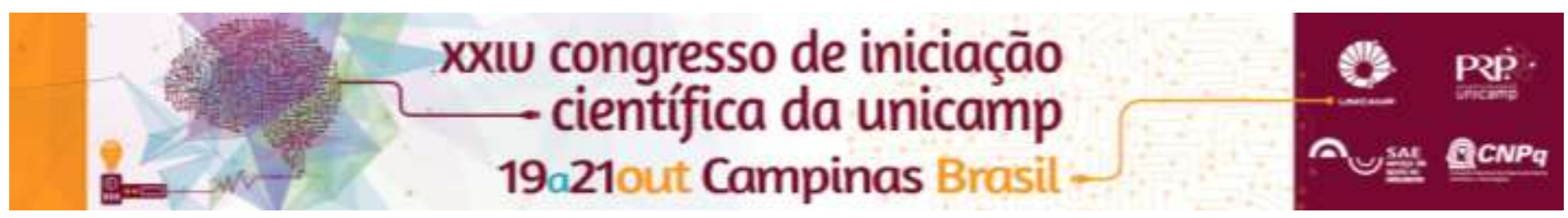

\title{
Fatores de risco e de proteção na saúde da mulher: uma perspectiva sistêmica
}

\section{Paula R. S. Gomes, Wagner L. Machado}

\section{Resumo}

O presente estudo buscou identificar fatores de risco e proteção sobre a saúde emocional e física de mulheres. Para isso, foram investigadas variáveis relacionadas ao perfil sociodemográfico, qualidade de vida relacionada à saúde física, personalidade, depressão e estresse. Análises de correlação bivariadas e de rede foram utilizadas para identificar as relações entre as variáveis. A partir da análise de rede buscou-se mapear a dinâmica de inter-relações entre os fatores de risco e proteção. Com este estudo procurou-se identificar fatores relevantes para a epidemiologia de problemas de saúde emocional e física na população feminina.

\section{Palavras-chave:}

Saúde da mulher, qualidade de vida, análise de rede

\section{Introdução}

O termo qualidade de vida é definido como "a percepção do indivíduo de sua posição na vida no contexto da cultura e sistema de valores nos quais ele vive e em relação aos seus objetivos, expectativas, padrões e preocupações" (WHOQOL GROUP, 1995). Entender o conceito de qualidade de vida é fundamental para que se possam compreender os diversos aspectos envolvidos na saúde da mulher.

\section{Resultados e Discussão}

Figura 1. Rede com as variáveis estudadas

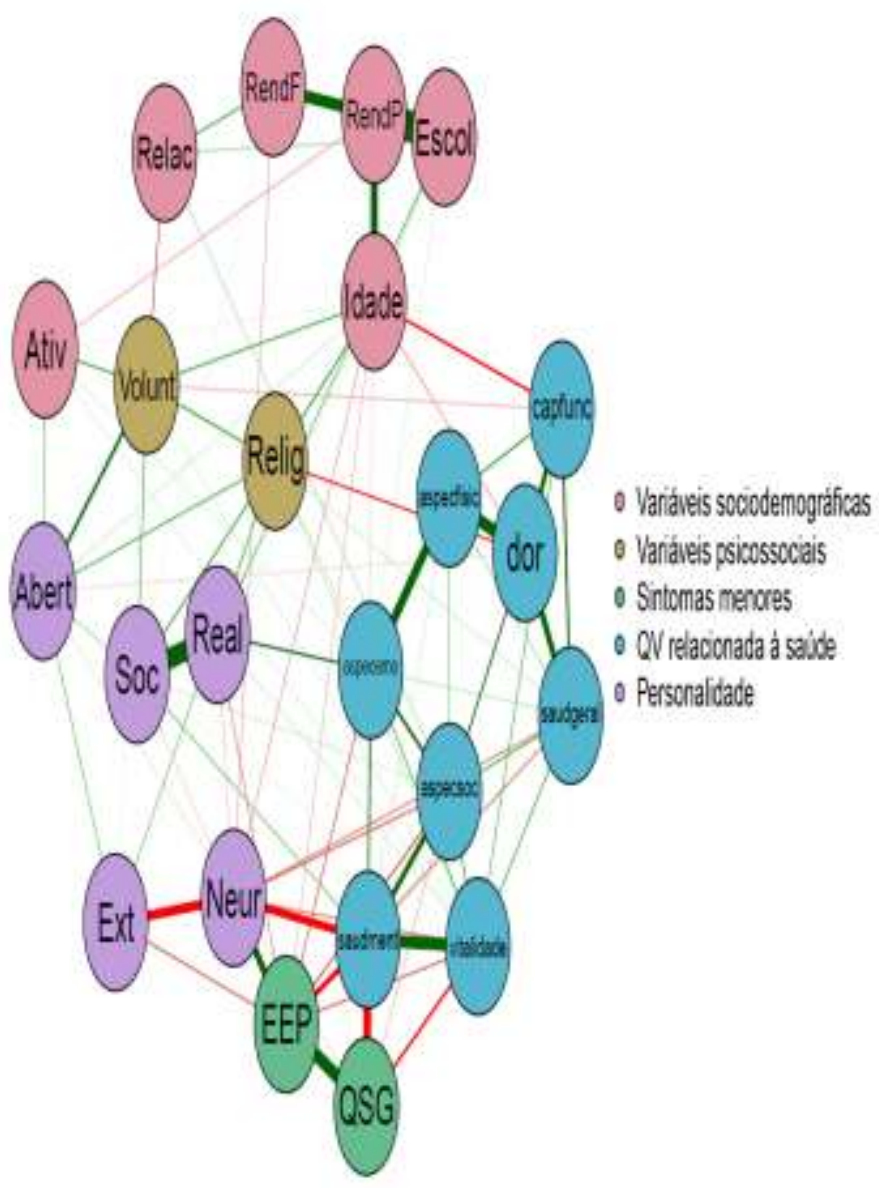

Os resultados obtidos destacam a relação negativa entre as variáveis dor e religião, o que indica que a religião pode atuar como uma estratégia (coping) para lidar com a dor. A variável saúde mental também se destaca, apresentando forte associação positiva com a variável aspectos sociais, estando em conformidade com o que aponta a literatura sobre a íntima relação mantida entre a pobreza e o baixo status econômico com resultados desfavoráveis no que se refere à saúde. $\mathrm{O}$ impacto do status socioeconômico, no caso das mulheres, é potencializado pelas diferenças de gênero que atua como fator de risco para a qualidade de vida, o bem estar e a saúde geral das mulheres. A variável saúde mental também apresenta relação, mas dessa vez negativa, com o neuroticismo. Sabe-se que esse fator da personalidade é associado a problemas de saúde mental e física, devido ao seu componente de vulnerabilidade e preocupação excessiva. Isso se explica pelo fato dos traços de personalidade poder atuar de forma a facilitar ou dificultar os diversos meios que o indivíduo dispõe para expressar suas emoções, agir na sociedade e lidar com as variáveis estressoras em sua vida.

\section{Conclusões}

Os programas que visam ações de promoção de saúde e prevenção de riscos e agravos para as mulheres devem ter a sua estrutura voltada para a mulher em sua integralidade, incluindo todas as questões relacionadas aos processos de saúde/doença que influenciam suas vidas. Além disso, é indispensável contextualizar essa mulher de acordo com a sua cultura, fatores biológicos, emocionais, econômicos e sociais de forma a preservar a sua identidade e particularidades.

\section{Agradecimentos}

Pontifícia Universidade Católica de Campinas.

WHOQOL Group. The World Health Organization quality of life assessment (WHOQOL): position paper from the World Health Organization. Soc Sci Med 1995; 41:1403-10. 